\title{
CORRECTION
}

\section{Correction to: Rbot: development of a robot-driven radio base station maintenance system}

Djamel Sadok ${ }^{1} \cdot$ Daniel Bezerra $^{1}$ (D) - Marrone Dantas ${ }^{1} \cdot$ Gabriel Reis $^{1} \cdot$ Pedro Leuchtenberg $^{1} \cdot$ Carolina Ledebour $^{1}$. Ricardo Souza $^{2}$. Silvia Lins ${ }^{2} \cdot$ Maria Marquezini $^{2} \cdot$ Judith Kelner $^{1}$

Published online: 9 November 2021

(c) Springer Nature Singapore Pte Ltd. 2021

\section{Correction to: \\ International Journal of Intelligent Robotics and Applications \\ https://doi.org/10.1007/s41315-021-00206-y}

In the original publication, the section 4 has been inadvertently misspelled as "4 Network onfrastructure". However, the corrected title should be "4 Network Infrastructure".

The original article has been corrected.

Publisher's Note Springer Nature remains neutral with regard to jurisdictional claims in published maps and institutional affiliations.

The original article can be found online at https://doi.org/10.1007/ s41315-021-00206-y.

Daniel Bezerra

daniel.bezerra@gprt.ufpe.br

1 Research Group on Networks and Telecommunication at UFPE-Brazil, Recife, Brazil

2 Ericsson Research, Indaiatuba, São Paulo, Brazil 